\section{Structured assessment of frailty in multiple myeloma as a paradigm of individualized treatment algorithms in cancer patients at advanced age}

\author{
Monika Engelhardt, ${ }^{1}$ Gabriele Ihorst, ${ }^{2}$ Jesus Duque-Afonso, ${ }^{1}$ Ulrich Wedding, ${ }^{3}$ \\ Ernst Spät-Schwalbe, ${ }^{4}$ Valentin Goede, ${ }^{5}$ Gerald Kolb, ${ }^{6}$ Reinhard Stauder ${ }^{7}$ and \\ Ralph Wäsch ${ }^{1}$
}

${ }^{1}$ Department of Medicine I, Hematology, Oncology and Stem Cell Transplantation, Medical Center - University of Freiburg, Faculty of Medicine, University of Freiburg, Freiburg, Germany; ${ }^{2}$ Clinical Trials Center Freiburg, Faculty of Medicine, University of Freiburg, Germany; ${ }^{3}$ Palliativmedizin Universitätsklinik Jena, Jena, Germany; ${ }^{4}$ Vivantes Klinikum Spandau, Innere Medizin, Hämatologie, Onkologie, Palliativmedizin, Berlin, Germany; ${ }^{5}$ Geriatrie Köln, St. Marien-Hospital, Köln, Germany; ${ }^{6}$ Bonifatius Hospital Lingen, Medizinische Klinik, Fachbereich Geriatrie, Akademisches Lehrkrankenhaus der Westfälischen Wilhelms-Universität Münster, Münster, Germany and ${ }^{\top}$ Universitätsklinik für Innere Medizin V (Hämatologie und Onkologie), Medizinische Universität Innsbruck, Innsbruck, Austria

\section{Introduction}

Life expectancy and incidence of cancer have substantially increased, the latter being closely interlinked to our longevity. Today, 617 million people are $\geq 65$ years; by 2050 , this number will have reached 1.6 billion, nearly $20 \%$ of the world's population, and the number of "very old" ( $>80$ years) will have more than tripled. ${ }^{1}$ This aging of the population involves enormous changes to patient care. For the moment, the most profound changes are to be seen in Japan, Europe and North America. Major risk factors associated with aging include cancer (also multiple cancers in a single patient), ${ }^{2}$ and cardiovascular and neurodegenerative diseases, all requiring long-term care. Therefore, especially high-income countries are obliged to meet the challenges.

Multiple myeloma $(\mathrm{MM})$, as one example of cancer, and the $2^{\text {nd }}$ most frequent hematologic malignancy, affects adults of all ages, but is primarily a disease of the elderly. The highest burden of MM-related deaths occurs among persons between 65 and 84 years of age..$^{3.7}$ Similarly to the situation in several other types of cancers, management of older MM patients is more demanding due to their often impaired organ function, underlying comorbidities, and co-existing frailty, which may increase therapy-related toxicity, and lead to dose reduction and shorter treatment endurance. ${ }^{3,4,6-9}$ The high prevalence of geriatric impairments is increasingly being recognized, but is not always easily detectable without an objective assessment., ${ }^{3,6,7}$ Our goal today involves reducing the risk of under-treating fit patients and overtreating those who are frail. ${ }^{5,10-12}$ Although eligibility criteria for studies of anti-cancer/-MM agents have traditionally relied on age cut-offs and performance status, geriatric and MM-specific frailty assessments are just beginning to be incorporated into more accurate stratification plans of treatment algorithms. ${ }^{6,711,12}$ Similarly to MM patients, geriatric assessments (GA) have been defined for patients with chronic lymphocytic leukemia (CLL) ${ }^{8,13,14}$ and myelodysplastic syndrome (MDS), ${ }^{15,16}$ where determination of frailty versus fitness has moved into clinical practice. However, solutions as to how they might be more uniformly used and valued in their daily pratice have not been fully determined.

Recommendations of the geriatric oncology working groups (i.e. German Society of Geriatrics/German Society of Hematoloogy\&Oncology) have suggested GA-tools to check comorbidity in patients aged $\geq 70$ years via the Charlson Comorbidity Index (CCI), cognition via the Mini Mental test (MMST), activity/instrumental activity of daily living (ADL/IADL), mobility via the Timed Up and Go test, depression via the geriatric depression scale (GDS), and nutrition via body mass index (BMI) and Mini Nutritional Status. ${ }^{6,71,1,12,17}$ While these GAtools have been established and validated, their execution is time-consuming, an additional workforce is needed, and the involvement of a geriatric team is advisable. . $7,7,11,12,17$ Whether shorter frailty scores in cancer patients may substitute and/or add to GA-tools is being pursued in single- and multi-center trials (Table 1).
Ferrata Storti Foundation

\author{
Haematologica 2020 \\ Volume 105(5):1183-1188
}

The results were presented in part at the 'American Society of Hematology' (ASH) meetings and the 'German, Austrian and Swiss annual Hematology \& Oncology meetings' (DGHO)

\section{Correspondence:}

MONIKA ENGELHARDT

monika.engelhardt@uniklinik-freiburg.de

Received: November 14, 2019.

Accepted: January 30, 2020.

Pre-published: April 2, 2020.

doi:10.3324/haematol.2019.242958

Check the online version for the most updated information on this article, online supplements, and information on authorship \& disclosures: www.haematologica.org/content/105/5/1183

\section{(C)2020 Ferrata Storti Foundation}

Material published in Haematologica is covered by copyright. All rights are reserved to the Ferrata Storti Foundation. Use of published material is allowed under the following terms and conditions:

https://creativecommons.org/licenses/by-nc/4.0/legalcode. Copies of published material are allowed for personal or internal use. Sharing published material for non-commercial purposes is subject to the following conditions:

https://creativecommons. org/licenses/by-nc/4.0/legalcode, sect. 3. Reproducing and sharing published material for commercial purposes is not allowed without permission in writing from the publisher. 
The aim of this commentary is to define strategies in MM patients, and explore how frailty assessment may be employed in clinical practice and clinical trials.

\section{Instruments to assess vulnerability due to increased treatment options}

The epidemiologic and biologic considerations of elderly MM patients, with widely expanding treatment options, have motivated global efforts to validate simple instruments to assess vulnerability of patients, test them in their clinical significance to predict treatment outcome [overall survival (OS) and progression-free survival (PFS)], occurrence of severe adverse events, and to tailor treatment with more or less intensified regimens. ${ }^{11,12,18}$

Under-treatment of fit elderly patients has been demonstrated to occur more frequently than over-treatment. ${ }^{12}$ Under-treatment may prevent improvement of organ function, while over-treatment of frail patients can induce unnecessary morbidity and mortality. Both instances reduce patients' health-related quality of life (HROOL). In a study that assessed HROOL across $>16,000$ cancer survivors, those with MM were among those with the lowest HRQOL scores, highlighting the urgent need for this to be improved and for frequent reassessment of HROOL in cancer patients. ${ }^{19}$ The art of managing elderly MM patients involves balancing competing disease-related and patient-specific factors and to make adequate treatment decisions.

Numerous induction (and relapse) MM-treatment options are available today. These include bortezomibcyclophosphamide-dexamethasone (VCD), bortezomiblenalidomide-dexamethasone (VRD or VTD), bortezomibmelphalan-prednisone (VMP) or antibody-combinations, autologous stem cell transplantation (ASCT) and 2-drug combinations, such as lenalidomide-dexamethasone (Rd), bortezomib-dexamethasone (Vd), and others. ${ }^{3,2022}$ These largely expanded therapeutic strategies, including immunotherapies ${ }^{23}$ have significantly evolved in recent years, but the beneficial effect is not seen across the age spectrum, with intermediate-fit or frail patients not obtaining the maximal benefit from such new treatment. Part of this failure to achieve benefit relates to the host biology of older patients. Therefore, there is an unmet need to give the right therapy to the patient most suited to benefit from it; the starting point for this approach is an appropriate classification of who is fit and who is frail.

Table 1. Selected clinical trials in multiple myeloma patients with frailty assessments included therein.

\begin{tabular}{|c|c|c|c|c|c|c|c|}
\hline$\#$ & $\begin{array}{l}\text { Institution } \\
\text { performing } \\
\text { the analysis }\end{array}$ & Trial title & Phase & Trial\# & $\begin{array}{l}\text { Retro- Vs. } \\
\text { prospective }\end{array}$ & $\begin{array}{l}\text { N. of } \\
\text { patients }\end{array}$ & Results / Study specifics \\
\hline 1 & $\begin{array}{l}\text { University of } \\
\text { Freiburg } \\
\text { (UKF) }\end{array}$ & Allogeneic (allo)-SCT & IV & NCT00655343 & Retrospective & 109 & $\begin{array}{l}\text { R-MCI did improve from } 4 \text { before to } 3 \text { after allo- } \\
\text { SCT. Renal function and age declined over time, } \\
\text { but did not neccessarily decrease QoL measures } \\
\text { after allo-SCT in long-term survivors. }\end{array}$ \\
\hline 2 & UKF & VBDD & I/ II & NCT01394354 & Prospective & 33 & $\begin{array}{l}\text { QoL improved in responsive pts: both frailty } \\
\text { scores and functional tests were used and showed } \\
\text { R-MCI improvement as well as of other frailty } \\
\text { scores and functional tests. }\end{array}$ \\
\hline 3 & Ohio State & $\begin{array}{l}\text { Frailty + functional } \\
\text { assessment in MM }\end{array}$ & $\begin{array}{c}\text { IV } \\
\text { bservationa }\end{array}$ & NCT02033928 & Prospective & 111 & $\begin{array}{l}\text { Change in Comprehensive Frailty Assessment: } \\
\text { before and after transplant (Tx) and non-Tx pts. } \\
\text { Study ongoing. }\end{array}$ \\
\hline 4 & $\begin{array}{l}\text { City of Hope }+ \\
\text { University of } \\
\text { Rochester }\end{array}$ & $\begin{array}{l}\text { Touchscreen-based } \\
\text { geriatric and functional } \\
\text { assessment }\end{array}$ & IV & NCT03068637 & Prospective & 165 & $\begin{array}{l}\text { Limited pt time required for survey completion } \\
\text { and provider time for results review show mGA } \\
\text { can be incorporated into clinical workflow. } \\
\text { Real-time mGA results indicating fit/frailty status } \\
\text { influenced treatment decisions. }\end{array}$ \\
\hline 5 & $\begin{array}{l}\text { Torino, } \\
\text { GIMEMA }\end{array}$ & $\begin{array}{l}\text { Rd } v s \text {. Rd-R in unfit MM } \\
\text { pts }\end{array}$ & II & NCT02215980 & Prospective & 210 & $\begin{array}{l}\text { Rd-R improved event-free survial (EFS) end points } \\
\text { in unfit MM pts. First results shown at ASH } 2018 \text {. }\end{array}$ \\
\hline 6 & $\begin{array}{l}\text { Indiana } \\
\text { University }\end{array}$ & $\begin{array}{l}\text { Maia randomization: } \\
\text { standard Dara-Rd vs. } \\
\text { reduction in frail pts }\end{array}$ & $\begin{array}{l}\text { II, } \\
\text { open label }\end{array}$ & NCT04223661 & Prospective & 44 & $\begin{array}{l}\text { Dara-Rd } v \text { s. reduced dose with frailty index } \geq 2 \text {. } \\
\text { Study ongoing. }\end{array}$ \\
\hline 7 & HOVON 143 & $\begin{array}{l}\text { Efficacy and tolerability } \\
\text { of Ixa-Dara-dex in unfit } \\
\text { and frail NDMM pts }\end{array}$ & II & NTR6297 & Prospective & $\begin{array}{c}\mathrm{n}=65 \\
\text { unfit, } \\
\mathrm{n}=67 \text { frail } \\
\text { pts }\end{array}$ & $\begin{array}{l}\text { Dose-adjustment feasible and advisable, but early } \\
\text { mortality still occurring. } \\
\text { Study ongoing, early ASH results shown 2019: } \\
\# 695 \text {. }\end{array}$ \\
\hline 8 & $\begin{array}{l}\text { University of } \\
\text { Leeds, UK } \\
\text { study group }\end{array}$ & $\begin{array}{l}\text { FiTNEss (Frailty-adjusted } \\
\text { therapy in Tx Non- } \\
\text { Eligible pts with NDMM) }\end{array}$ & d & NCT03720041 & Prospective & 740 & $\begin{array}{l}\text { IRd according to frailty score - randomization } \\
\text { into } 4 \text { groups. } \\
\text { Study ongoing. }\end{array}$ \\
\hline
\end{tabular}

pts: patients,\#: number, UKF: University of Freiburg Medical Center, allo-SCT: allogeneic stem cell transplantation, R-MCI: Revised Myeloma Comorbidity Index; Tx: transplantation;VBDD: vorinostat-bortezomib-doxorubicin-dexamethason treatment in relapsed/refractory multiple myeloma (RRMM), QoL: Quality of life; ND MM pts: newly diagnosed MM patients; GIMEMA: Italian study group. Rd vs. RD-R: Lenalidomide-dexamethason $v$ s. continuation of reduced lenalidomide doses without dexamethason in Rd-R, IRd: ixazomib-lenalidomide-dexamethasone; Ixa-Dara-Dex: ixazomib-daratumumab-dexamethasone; Dara-RD: daratumumab-lenalidomide-dexamethasone. For other studies in MM see also Mina et al. ${ }^{51}$ 


\section{Risk parameters in multiple myeloma}

That age alone is a much less well-suited discriminator for treatment designation has been shown via various risk parameters and comorbidity scores, that are usually described as patient-related factors. ${ }^{1,1,2,24-26}$ These involve simple measures of daily activity, such as constitution via Eastern Cooperative Oncology Group (ECOG) or Karnofsky performance status (KPS), organ function, and comorbidities. However, because the KPS/ECOG do not reflect the entire functional status of cancer patients, advances in defining patient fitness more precisely are warranted. In an analysis of 466 consecutive MM patients, the median KPS was determined to be $90 \%$, although a precise reassessment showed this was actually $60 \%$, i.e. $30 \%$ lower than that estimated by physicians. This clearly demonstrates that both KPS/ECOG are often over-estimated, and a more precise frailty assessment is valuable. ${ }^{25}$ In a subsequent analysis, 13 comorbid conditions were assessed in 801 patients. These were graded and rated according to the Common Terminology Criteria for Adverse Events (CTCAE 4.03), which included: renal-, lung- and KPS-impairment, cardiac, liver or gastrointestinal disease, disability, frailty, infection, thromboembolic events, peripheral neuropathy, pain, and secondary malignancies. In addition, age, cytogenetics via fluorescence in situ hybridization, renal function and lung disease were determined. The multivariate Cox proportional hazard model based on backward selection revealed five highly significant risks as relevant for OS: renal and lung function, KPS, age, and frailty (Fried definition). Score weights for comorbidities were determined on the basis of regression coefficients of the prognostic factors. ${ }^{12}$ Although impairment of organ function such as lung disease had been defined as having nothing to do with $\mathrm{MM}$, in line with other large MM study groups (such as both the German GMMG and DSMM study groups), patients with moderate and severe lung impairment and continued smoking habit were at substantial risk for treatment complications. ${ }^{11,12}$ We would, therefore, refrain from ASCT/allogeneic-SCT, triplet and quadruplet therapies in heavy smokers and/or those with impaired lung function. ${ }^{11,12,24-26}$ Moreover, disease-related factors add additional complexity in MM, such as cytogenetics, International Staging System (ISS)/revised (R)-ISS stage, bone marrow infiltration, and number of $C R A B$ ( $C$, hypercalcemia; R, renal impairment; A, anemia; B, bone lesions) symptoms. In addition, treatment-related factors, such as how quickly and for how long the disease responds to therapy, are critical..$^{27-29}$

\section{Frailty, organ impairment and myeloma scores}

In prior organ function analyses, ${ }^{11,1,2,24-26,30}$ the extent of frailty in MM patients was substantial: $60 \%$ for entire (mild to severe) and $40 \%$ for severe frailty. ${ }^{11,12}$ This led to the development of the revised myeloma comorbidity score (R-MCI). This R-MCI uses weights generated via multivariate risk factor assessment with the essential risks being included therein, such as: renal and lung function, KPS, frailty and age, with the option to add cytogenetics. ${ }^{11,12}$ Apart from organ impairment, cytogenetic aberrations corroborate with impaired OS in MM patients. The analysis confirmed that cytogenetics provide independent additional information, ${ }^{31-35}$ and that patients with unfavorable cytogenetics had higher disease stages, adverse laboratory values, and reduced organ and physical function. Although cytogenetics proved to be a relevant risk factor, the analysis confirmed that others, such as physical and organ conditions, are equally important. ${ }^{67,11,12,18}$ Moreover, development of the R-MCI showed that the multivariate risks (renal, lung function, KPS, age, frailty) defined patients as fit, intermediate-fit, and frail, which could be improved with inclusion of cytogenetics, (but which could still be used even if this information was unavailable). Weighting of the R-MCI verified that this 9-point score defines three patient groups with clearly different survival, ${ }^{12}$ which remained true regardless of treatment or age subgroups.

\section{Comparison of the R-MCI with others and current questions}

Comparison of the R-MCI with numerous others [CCI, Kaplan Feinstein (KF), Hematopoietic Cell Transplantation Comorbidity Index (HCT-CI/Sorer), ${ }^{12}$ the Satariano Index ${ }^{2426}$ or the International Myeloma Working Group (IMWG frailty score ${ }^{11}$ ) showed that they all divide patients into risk groups with substantially different OS. However, Brier scores determined the smallest prediction errors with the R-MCI. One reason for the comparability of the RMCI with others was that most include risks that have some relevance in MM, namely renal and lung function, and physical condition. Compared to the initial nonweighted $\mathrm{MCI}^{24-26}$ the R-MCI led to an improvement in group distinction, which highlights the relevance to further improve a risk score, as performed in subsequent analyses. ${ }^{11,12,2426,30}$ Various risk scores that are used in different institutions and within clinical trials in MM patients are summarized in Table 1. 18,36-38

The question is, therefore, whether one comorbidity score in MM should be put forward or whether more should be developed. Moreover, would harmonization and inclusion of biomarkers improve them ${ }^{29}$ Another question is if $\mathrm{MM}$ experts will use these scores and whether treatment decisions are being improved. ${ }^{40,41}$ Whether risks determined by a score result in changes in treatment decision has not been fully addressed. Given that MM primarily affects the elderly, whose vulnerabilities may change over time, it is also reasonable to incorporate serial GA throughout treatment in order to potentially modify therapy over time and incorporate this into tumorboards and treatment guidelines. For older, fit patients, intensive treatment with ASCT may be appropriate, while in the very frail, with GA and high R-MCIscores, end-of-life care discussions can be facilitated. ${ }^{10,42}$

\section{Concrete clinical designations of the use of the R-MCI}

1. We have included the R-MCI in the weekly MM tumorboard, where this is being scored before the patient is discussed at an interdisciplinary level. Web applications make it easy to obtain a score end result, as has been achieved for the R-MCI and IMWG-frailty scores. ${ }^{11,12,18,40}$ For the R-MCI, each patient's individual risk parameters will generate an R-MCI score. 
Training and validation analyses of the R-MCI showed well-discriminated risk profiles in terms of both PFS and OS for fit, intermediate fit, and frail patients. ${ }^{12}$ This was true both for more intensively and less intensively treated $\mathrm{MM}$ patients. ${ }^{12}$ Moreover, if $\mathrm{MM}$ patients were riskassessed via the R-MCI rather than the IMWG-frailty score, Kaplan-Meier analysis produced more clearly separated PFS and OS curves with the the R-MCI than with the IMWG-frailty score. ${ }^{11}$

Importantly, if patients are intermediate-fit or frail by $\mathrm{R}-\mathrm{MCI}$, precautions for dose reduction of systemic treatment can be made: i.e. if advanced frailty in MM patients is observed, dose reductions can be discussed, including whether the disease aggressiveness needs effective anti$\mathrm{MM}$ treatment to be performed in spite of the patient's frailty. Today, it seems important, given the widely different anti-MM treatment options, that the frailty scoring specifically warns $\mathrm{MM}$ experts that complications with intensive treatment may occur. As many precautions as possible can then be taken while treatment is being given, such as inpatient rather than outpatient treatment, observation on the ward until complications no longer occur, prophylactic medications, etc. In line with this, in their joint EMN-paper, ${ }^{7}$ the European Myeloma Network $(\mathrm{EMN})$ consensus has stated that in fit MM patients, efficient antimyeloma therapy with the aim of deep remission is key, whereas in unfit or frail patients, the priority is to maintain a good balance between therapy efficacy and safety.

2. Useful dose adaptations have been recommended for individual antimyeloma agents and are published as such in guidelines and chemotherapy manuals. ${ }^{6,7,43}$

3. The R-MCI has also been included in study protocols before therapy initiation and at the end of treatment. This can assess whether a patient's constitution did improve over time, and whether this was associated with myelo- ma response and better functional comorbidity tests (Table 1). ${ }^{21,44}$

4. The R-MCI has, indeed, allowed a patient's improved constitution to be demonstrated; this has also been assessed in rarer treatment scenarios, such as in younger, high-risk patients undergoing immunotherapy approaches, i.e. allo-SCT. Here, although patients grew older and renal function declined over time, the median R-MCI improved from 4 before allo-SCT to 3 after alloSCT (Table 1). ${ }^{23,45}$

5. In frail patients, being able to see if there is any deterioration in the R-MCI makes it easier to adapt or interrupt treatment. This underscores its clinical helpfulness. For example, since the QoL in a light chain (AL)-amyloidosis patient did not improve, even though hematologic response was achieved, the use of the R-MCI facilitated supportive treatment rather than continuation of extensive and expensive care..$^{10,46}$

6. Inclusion of the R-MCI in future study protocols at our center, and in discussion with both German MM study groups (DSMM and GMMG) is under way.

\section{Conclusions}

Although the IMWG-frailty score is a "reference" comorbidity index, ${ }^{18}$ others are more straightforward to use. The inclusion of "Lung function" in the R-MCI had been repeatedly requested by reviewers as a more objective measure than via the GOLD criteria, smoking status or dyspnea upon exertion, and is included in the diagnostic workup at our center (i.e. before intensive treatment, such as SCT). ${ }^{11,12,21,44-47}$ If unavailable, smoking status, its mandatory cessation before SCT/intensive treatment, no advanced GOLD criteria, and no dyspnea upon exertion have been used as substitutes in prior analyses. ${ }^{24-26}$

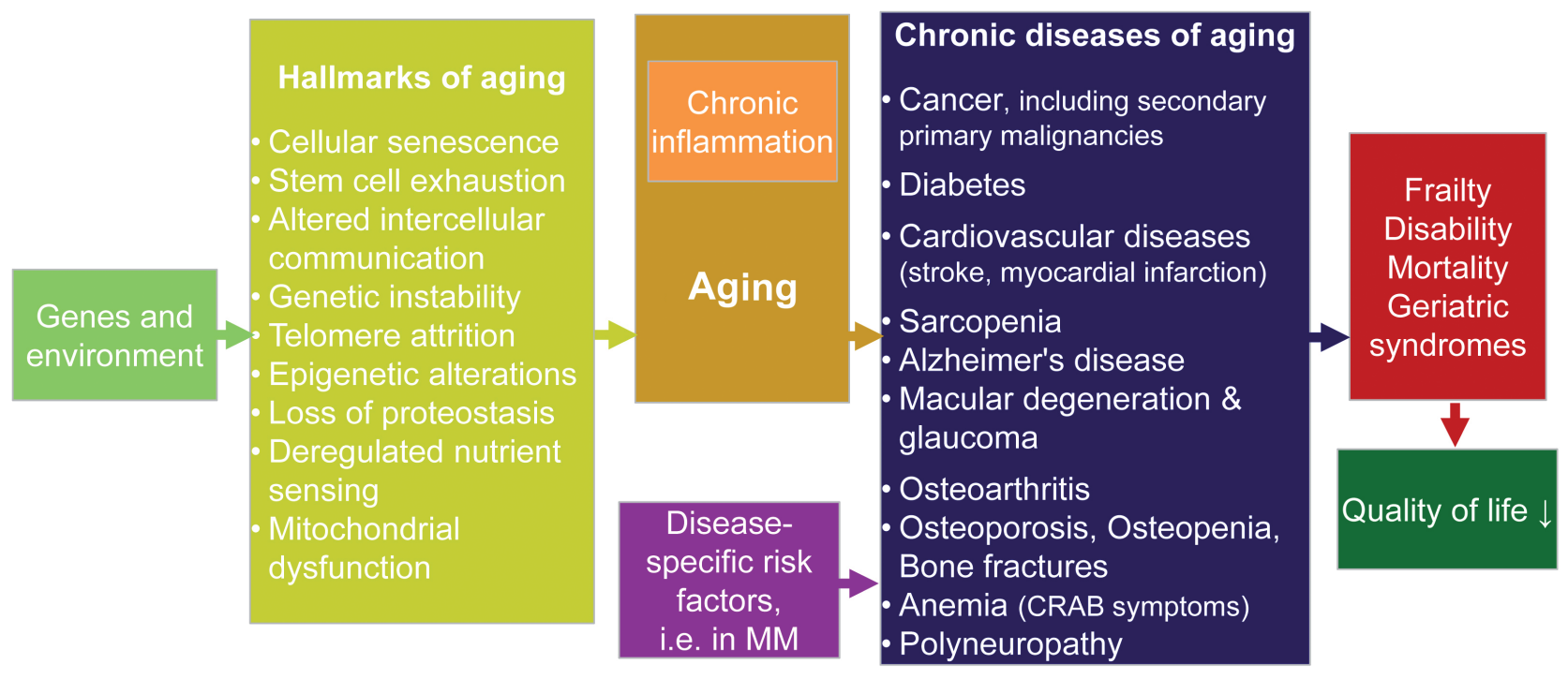

Figure 1. Environmental and genetic factors that influence key cellular processes and pathways defined as hallmarks of aging. Many pathways contribute to the creation of a chronic inflammatory stage and to aging. These in turn increase the risk of chronic disease of aging together with disease-specific risk factors, i.e. in multiple myeloma (MM): polyneuropathy, osteoporosis/osteopenia, bone fractures, anemia. All eventually induce frailty, disability, mortality and geriatric syndromes, and potentially decrease patients' quality of life (adapted and with permission of J. Campisi et al.) ${ }^{50}$ 
We have demonstrated the validity of the R-MCI as a valid prognostic instrument in large MM cohorts treated according to current standards. Based on existing recommendations, the R-MCI can be applied in routine clinical care, multicenter analyses and future clinical trials. It may be used in research to compare risk profiles of $\mathrm{MM}$ cohorts, to adjust for imbalanced risks, and to provide a basis to establish new clinical or biologic prognostic factors. Moreover, the R-MCI might be considered to be an integral part in the development of individualized riskadapted treatment strategies to further improve outcome in $\mathrm{MM}$. This includes correct use of resources, higher inclusion rates of older patients into clinical studies, and avoidance of under-supply for older but fit patients.

In the future, the R-MCI could also help to support treatment decisions, tolerability, and to avoid toxicity. Since any prospective comorbidity, frailty and disability evaluation can be time-consuming, we have implemented the R-MCI within a web-based technology application which allows a quick turnaround of results. ${ }^{48}$ Routine measurement of frailty in MM patients is, therefore feasible, and several analyses via R-MCI ${ }^{11,12}$ (or IMWG frailty scores ${ }^{18}$ with various adaptations ${ }^{6,47}$ ) are available.

All current developments in the field are enthusiastically welcomed, because more effective and individualized treatment offers an opportunity to further improve clinical outcomes, especially among older patients with hematologic malignancies. ${ }^{21,27,28,49}$ We have proven tools for a functional, more objective assessment to help guide every-day treatment, and these should be incorporated into tumor boards and may allow better trial comparability, as well as helping to guide trial design. It will be interesting to see whether, in the near future, these risk tools are readily implemented into clinical care and can improve patient management. We are entering an exciting era for research on aging, which holds unprecedented promise for increased patient lifespan, delaying pathologies of aging, allowing patients to grow old, and living a life full of purpose and well-being (Figure 1).,50 Future clinical trials that target the aging process and that study biomarkers and intervention programs face considerable challenges, but the potential rewards will far outweigh their risks. ${ }^{1,50}$

\section{Acknowledgments}

The authors thank distinguished IMWG, EMN, DSMM and GMMG experts, especially Drs. Thierry Facon (Lille), Hervé Avet-Loiseau (Toulouse), Alessandra Larocca, Sara Bringhen, Francesca Gay (Turin), Gordon Cook (Leeds), Sonja Zweegman (Amsterdam), Heinz Ludwig (Vienna), Hermann Einsele (Würzburg) and Hartmut Goldschmidt (Heidelberg) for their advice and recommendations. We are also grateful of the insightful comments of all myeloma experts and colleagues at the University Clinic Freiburg (UKF), for their inspiring work and thrive for $R$ MCI topics. The paper is dedicated to Dr. Sandra Maria Woerner, Maximillian Holler, Sophia Scheubeck, Katja Schoeller, Irina Surlan, Mandy Möller, Stefanie Ajayi, Amelie Rösner, Drs. Martina Kleber, Laura Gengenbach, Giulia Graziani, Maximillian Schinke, Heike Reinhardt, Stefan Müller, Matthias Weiß, Johannes Jung, Christine Greil, Michael Rassner, Cornelius Miething, Milena Pantic and Barbara Deschler (UKF, University of Basel and University of Würzburg) for their exceptional support. We are indebted to the interdisciplinary $M M$ tumorboard, the CCFF for incorporation of the R-MCI in its application modus and thank all MM patients who participated in our MM studies. We also thank the 3 insightful, knowledgeable reviewers for their critical comments, which have further improved this article.

\section{Funding}

This work was supported by the Deutsche Krebshilfe (grants 1095969 and 111424 [to ME and RW]) and Verein SeniorenKrebshilfe (R.S.).

\section{References}

1. Dzau VJ, Inouye SK, Rowe JW, Finkelman E, Yamada T. Enabling Healthful Aging for All - The National Academy of Medicine Grand Challenge in Healthy Longevity. N Engl J Med. 2019;381(18):1699-1701.

2. Engelhardt $M$, Ihorst $G$, Landgren $O$, et al. Large registry analysis to accurately define second malignancy rates and risks in a wellcharacterized cohort of 744 consecutive multiple myeloma patients followed-up for 25 years. Haematologica. 2015;100(10): 1340-1349.

3. Engelhardt M, Terpos E, Kleber M, et al. European Myeloma Network recommendations on the evaluation and treatment of newly diagnosed patients with multiple myeloma. Haematologica. 2014;99(2):232242.

4. Bringhen S, Mateos MV, Zweegman S, et al. Age and organ damage correlate with poor survival in myeloma patients: meta-analysis of 1435 individual patient data from 4 randomized trials. Haematologica. 2013;98(6): 980-987.

5. Laubach J. Initial Therapy in Older Patients with Multiple Myeloma. N Engl J Med. 2019;380(22):2172-2173.
6. Zweegman S, Engelhardt M, Larocca A, EHA SWG on 'Aging and Hematology.' Elderly patients with multiple myeloma: towards a frailty approach? Curr Opin Oncol. 2017;29(5):315-321.

7. Larocca A, Dold SM, Zweegman S, et al. Patient-centered practice in elderly myeloma patients: an overview and consensus from the European Myeloma Network (EMN). Leukemia. 2018;32(8):1697-1712.

8. Goede V, Stauder R. Multidisciplinary care in the hematology clinic: Implementation of geriatric oncology. J Geriatr Oncol. 2019;10(3):497-503.

9. Bron D, Ades L, Fulop T, Goede V. Aging and malignant hemopathies. Haematologica. 2015;100(5):571-574.

10. Antoine-Pepeljugoski C, Braunstein MJ. Management of Newly Diagnosed Elderly Multiple Myeloma Patients. Curr Oncol Rep. 2019;21(7):64

11. Engelhardt M, Dold SM, Ihorst G, et al. Geriatric assessment in multiple myeloma patients: validation of the International Myeloma Working Group (IMWG) score and comparison with other common comorbidity scores. Haematologica. 2016;101(9): 1110-1119.

12. Engelhardt M, Domm A-S, Dold SM, et al. A concise revised Myeloma Comorbidity
Index as a valid prognostic instrument in a large cohort of 801 multiple myeloma patients. Haematologica. 2017;102(5):910921

13. Eichhorst B, Hallek M, Goede V. Management of unfit elderly patients with chronic lymphocytic leukemia. Eur J Intern Med. 2018;58:7-13.

14. Stauder R, Eichhorst B, Hamaker ME, et al. Management of chronic lymphocytic leukemia (CLL) in the elderly: a position paper from an international Society of Geriatric Oncology (SIOG) Task Force. Ann Oncol. 2017;28(2):218-227.

15. Stauder R, Yu G, Koinig KA, et al. Healthrelated quality of life in lower-risk MDS patients compared with age- and sexmatched reference populations: a European LeukemiaNet study. Leukemia. 2018;32(6): 1380-1392.

16. Burgstaller S, Wiesinger $\mathrm{P}$, Stauder R. Myelodysplastic Syndromes in the Elderly: Treatment Options and Personalized Management. Drugs Aging. 2015;32(11): 891-905.

17. Friedrich C, Kolb G, Wedding U, Pientka L, Interdisziplinäre Arbeitsgruppe der DGHO/DGG. Comprehensive geriatric assessment in the elderly cancer patient. Onkologie. 2003;26(4):355-360. 
18. Palumbo A, Bringhen S, Mateos MV, et al. Geriatric assessment predicts survival and toxicities in elderly myeloma patients: an International Myeloma Working Group report. Blood. 2015;125(13):2068-2074.

19. Kent EE, Ambs A, Mitchell SA, et al. Healthrelated quality of life in older adult survivors of selected cancers: data from the SEERMHOS linkage. Cancer. 2015;121(5):758-765.

20. Facon T, Kumar S, Plesner T, et al. Daratumumab plus Lenalidomide and Dexamethasone for Untreated Myeloma. N Engl J Med. 2019;380(22):2104-2115

21. Gengenbach L, Reinhardt H, Ihorst G, et al. Navigating the changing multiple myeloma treatment landscape: clinical practice patterns of MM patients treated in- and outside German DSMM study group trials $<$ sup $/>$. Leuk Lymphoma. 2018;59(11):2692-2699.

22. Einsele H, Engelhardt M, Tapprich C, et al. Phase II study of bortezomib, cyclophosphamide and dexamethasone as induction therapy in multiple myeloma: DSMM XI trial. Br J Haematol. 2017;179(4):586-597.

23. Köhler M, Greil C, Hudecek M, et al. Current developments in immunotherapy in the treatment of multiple myeloma. Cancer. 2018;124(10):2075-2085

24. Kleber M, Ihorst G, Terhorst $M$, et al. Comorbidity as a prognostic variable in multiple myeloma: comparative evaluation of common comorbidity scores and use of a novel MM-comorbidity score. Blood Cancer J. 2011;1(9):e35.

25. Kleber M, Ihorst G, Gross B, et al. Validation of the Freiburg Comorbidity Index in 466 multiple myeloma patients and combination with the international staging system are highly predictive for outcome. Clin Lymphoma Myeloma Leuk. 2013;13(5):541551.

26. Kleber M, Ihorst G, Udi J, et al. Prognostic risk factor evaluation in patients with relapsed or refractory multiple myeloma receiving lenalidomide treatment: analysis of renal function by eGFR and of additional comorbidities by comorbidity appraisal. Clin Lymphoma Myeloma Leuk. 2012; 12(1):38-48.

27. Hieke S, Kleber M, König C, Engelhardt M, Schumacher M. Conditional Survival: A Useful Concept to Provide Information on How Prognosis Evolves over Time. Clin. Cancer Res. 2015;21(7):1530-1536.

28. Schumacher M, Hieke S, Ihorst G, Engelhardt M. Dynamic prediction: A challenge for biostatisticians, but greatly needed by patients, physicians and the public. Biom J. 2019 Mar 25. [Epub ahead of print]

29. Caers J, Garderet L, Kortüm KM, et al. European Myeloma Network recommenda- tions on tools for the diagnosis and monitoring of multiple myeloma: what to use and when. Haematologica. 2018;103(11):17721784.

30. Kleber M, Ihorst G, Deschler B, et al. Detection of renal impairment as one specific comorbidity factor in multiple myeloma: multicenter study in 198 consecutive patients. Eur J Haematol. 2009;83(6):519-527.

31. Corre J, Munshi N, Avet-Loiseau H Genetics of multiple myeloma: another heterogeneity level? Blood. 2015;125(12):18701876.

32. Moreau P, Cavo M, Sonneveld P, et al. Combination of international scoring system 3, high lactate dehydrogenase, and $\mathrm{t}(4 ; 14)$ and/or del(17p) identifies patients with multiple myeloma (MM) treated with front-line autologous stem-cell transplantation at high risk of early MM progressionrelated death. J Clin Oncol. 2014;32(20): 2173-2180.

33. Neben K, Jauch A, Bertsch U, et al. Combining information regarding chromosomal aberrations $\mathrm{t}(4 ; 14)$ and $\operatorname{del}(17 \mathrm{p} 13)$ with the International Staging System classification allows stratification of myeloma patients undergoing autologous stem cell transplantation. 2010;95(7):1150-1157.

Haematologica.

34. Palumbo A, Avet-Loiseau $\mathrm{H}$, Oliva S, et al. Revised International Staging System for Multiple Myeloma: A Report From International Myeloma Working Group. J Clin Oncol. 2015;33(26):2863-2869.

35. Avet-Loiseau H, Durie BGM, Cavo M, et al. Combining fluorescent in situ hybridization data with ISS staging improves risk assessment in myeloma: an International Myeloma Working Group collaborative project. Leukemia. 2013;27(3):711-717.

36. Binder M, Rajkumar SV, Ketterling RP, et al. Substratification of patients with newly diagnosed standard-risk multiple myeloma. Br J Haematol. 2019;185(2):254-260.

37. Milani P, Vincent Rajkumar S, Merlini G, et al. N-terminal fragment of the type-B natriuretic peptide (NT-proBNP) contributes to a simple new frailty score in patients with newly diagnosed multiple myeloma. Am J Hematol. 2016;91(11):1129-1134.

38. Cook G, Royle K-L, Pawlyn C, et al. A clinical prediction model for outcome and therapy delivery in transplant-ineligible patients with myeloma (UK Myeloma Research Alliance Risk Profile): a development and validation study. Lancet Haematol. 2019;6(3):e154-e166.

39. Pallis AG, Hatse S, Brouwers B, et al. Evaluating the physiological reserves of older patients with cancer: the value of potential biomarkers of aging? I Geriatr Oncol. 2014;5(2):204-218

40. Engelhardt M, Selder R, Pandurevic M, et al. [Multidisciplinary Tumor Boards: Facts and Satisfaction Analysis of an Indispensable Comprehensive Cancer Center Instrument]. Dtsch Med Wochenschr. 2017;142(9):e51 e60.

41. Soto-Perez-de-Celis E, Li D, Yuan Y, Lau YM, Hurria A. Functional versus chronological age: geriatric assessments to guide decision making in older patients with cancer Lancet Oncol. 2018;19(6):e305-e316.

42. Abel GA, Klepin HD. Frailty and the management of hematologic malignancies Blood. 2018;131(5):515-524

43. Engelhardt M, Mertelsmann R, Duyster J. Das Blaue Buch. Springer; 2020.

44. Waldschmidt JM, Keller A, Ihorst G, et al. Safety and efficacy of vorinostat, bortezomib, doxorubicin and dexamethasone in a phase I/II study for relapsed or refractory multiple myeloma (VERUMM study: vorinostat in elderly, relapsed and unfit multiple myeloma). Haematologica. 2018;103(10):e473-e479

45. Greil C, Engelhardt M, Ihorst $G$, et al Allogeneic transplantation of multiple myeloma patients may allow long-term survival in carefully selected patients with acceptable toxicity and preserved quality of life. Haematologica. 2019;104(2):370379

46. Küchlin S, Duffner J, Scheubeck S, et al Kidney embolization induces prompt organ response in a 86-year-old patient with MGRS-related AL-amyloidosis. Hemodial Int. 2019;23(2):E59-E64

47. Facon T, Dimopoulos MA, Meuleman N, et al. A simplified frailty scale predicts outcomes in transplant-ineligible patients with newly diagnosed multiple myeloma treated in the FIRST (MM-020) trial. Leukemia. 2020;34(1):224-233

48. Engelhardt M, Dold SM, Ihorst G, Knaus J Schumacher M. R-MCI webpage. 2015.

49. Kumar SK, Dispenzieri A, Lacy MO, et al Continued improvement in survival in multiple myeloma: changes in early mortality and outcomes in older patients. Leukemia. 2014;28(5):1122-1128

50. Campisi J, Kapahi P, Lithgow GJ, et al. From discoveries in ageing research to therapeutics for healthy ageing. Nature. 2019;571 (7764):183-192.

51. Mina R, Bringhen S, Wildes TM, Zweegman $\mathrm{S}$, Rosko AE. Approach to the Older Adult With Multiple Myeloma. ASCO Educational Book 2019; vol 39. doi.org/10.1200/EDBK_239067.Am Soc Clin Oncol Educ Book. 2019;39:500-518. 